\title{
Education of the Whole Child: Fact or Fiction?
}

\author{
Paul Hunsicker \\ Guy Reiff
}

\begin{abstract}
Physical education teaches basic life principles as well as motor skills that have long-lasting benefits. Yet, say these authors, it is usually the first curricular area to suffer school budget cuts. Criteria for a good physical education program are described, with the implication that if the subject is properly taught it is more difficult to indiscriminately cut.
\end{abstract}

Educators have subscribed to the concept of "education of the whole child" for many years. Few administrators, in fact, would question the idea's worth. However, as soon as the budget gets tight, school boards react with remarkable consistency by singling out art, music, and/or physical education as the sacrificial lamb. All three are important fields of study, but this article limits itself to remarks about physical education.

\section{Physical Education Benefits Everyone}

To begin with, if educators accept the thesis of meeting the needs of the individual student, who is willing to say that a course in physical education might not be of greater benefit to some students than exposure to the more academic courses? Test results show that a certain percentage of any junior high school population makes hardly any progress in traditional courses during the year. About all you can conclude is that the students were registered for a period of time, but learning was nil. Any school-wide mandate eliminating physical education could conceivably be depriving students of experience which might be more meaningful than just being a body in residence for three or four years.

Paul Hunsicker and Guy Reiff teach in the Department of Physical Education, the University of Michigan, Ann Arbor. Reiff is chairman of the Professional Preparation Program. 
To take a more positive look at physical education, here is some food for thought. A good program in physical education (more on "good" later) can make highly significant contributions to all students. In the first place, physical education courses have a greater concern with the principles of healthful living, i.e., proper rest, exercise, weight control, etc., than any other course in the curriculum. Secondly, physical education programs can be equally challenging to students with IQ's of 70 or 170 , as well as those in between. In addition, the physically or mentally handicapped can enjoy and profit from physical education as well as the superstar.

\section{Permanence of Physical Skills}

Another source of gratification to the teacher of physical education is the relative permanence of many of the skills which he teaches. For example, when a pupil learns to swim, he is never again a nonswimmer. The ability to swim remains with him to enjoy throughout the rest of his life. The same holds true for numerous other motor skills. Think of the game situations present in physical education programs where the student gets an opportunity to make decisions under physical or emotional stress. Or consider the wonderful chances for competition or cooperation present in games.

It should be emphasized that competition and cooperation are by no means mutually exclusive. Competitive sports are replete with instances where the performer had to sublimate his own interests and ambitions for the good of the team. Anyone who has attained a high level of performance is aware of the sacrifices he made to reach the pinnacle. All of these experiences can have a salutary effect on the student's character. At this juncture the reader might ask, "If physical education has all the aforementioned virtues, why is it continually appearing on the budgetary chopping block?"' Let's examine a few possible reasons.

In the first place the public is ill-informed regarding what constitutes a good physical education program as well as some of the possible benefits of it. In the minds of all too many, physical education is conceived as interscholastic sports while, in reality, this is only one phase of a good program. Partly because of this misconception the public has little or no expected outcomes to demand of the teacher of physical education. The obvious sequel is that no one is around to harass the principal, and since he has enough squawks from other quarters he makes little if any demands from the physical education teacher. Then, too, the principal isn't always certain as to what constitutes a good physical education program. Many principals consider a program "good" if there are no fights in the gymnasium and the students are "dressed out" and shower every day. Evaluations of 
student achievement in physical education somehow get overlooked by school administrators, yet they obviously would never overlook these criteria for other subjects such as mathematics, English, or science.

The blame for the gaps in the public's knowledge of the field must be placed primarily on the physical educator. Over the years he did a great job selling interscholastic sports but a poor one selling physical education. In his defense, it must be recognized that the communications media as well as the public have been more receptive to press releases covering the interscholastic program rather than stories about the rest of the physical education programs.

\section{Criteria for Good Program}

At this point, it might be helpful to examine some selected criteria of a good physical education program. These could serve as useful guidelines for the administrator or the lay public.

The following statements seem germane:

1. Classes should be conducted as instructional periods and not merely as play periods or as a recess.

2. The program should be challenging to the entire school population. To accomplish this the physical education program is usually fractionated into: (a) the regular instructional program, (b) the adapted program for students with specific problems, (c) the intramural and recreational program and, (d) the interscholastic program.

3. The program should be spelled out in writing and should cover the objectives, program content, and means of evaluation.

4. The content should be geared to the developmental level of the student and should offer new challenges as soon as the student is ready for them. In this light, there should be terminal points in the instructional programs so the student isn't faced with basketball or any other single sport throughout his school years. Let the intramural or interscholastic program serve the skilled performer who wants to specialize.

5. The program should include instruction in individual sports that are more apt to be continued through adult life. More exposure to a sport, however, will not guarantee lifetime participation. Encouragement to continue participation might help.

6. Periodic and continual evaluations should be conducted to determine whether program objectives are being met. Standardized tests for physical fitness, motor skills, and concepts of movement exist and should be utilized. 
7. Communications with students, parents, and supervisory personnel should be planned as standard operation procedure.

8. The program should take cognizance of the unusual opportunities available in physical education for inculcating the principles of healthful living.

In order to achieve the above mentioned criteria, the principal, the school board, and the public must recognize personnel, equipment, and facility needs of the physical educator. Don't expect him to function effectively in classes of 50 to 100 students in space designed for a seminar and armed with one basketball. Many school principals have encouraged the use of physical education classes as a "dumping ground" for troublesome students from other classes, or for those who have a free hour. Give the physical educator support and then hold him to the same standards of teaching that you expect of the other members of the faculty. Why not make educating the whole child truly a fact, not fiction?

\section{SAT Scores Decline}

The College Entrance Examination Board reports that average scores on the Scholastic Aptitude Test earned by 1975 high school graduates declined 10 points on the verbal part and eight points on the mathematical section below the scores of 1974 graduates.

The report, College-Bound Seniors, 1974-75, also shows:

- For the first time, more women than men taking the SAT.

- Declines in scores on most Achievement Tests.

- A continuing increase in women's aspirations to study for a graduate degree. 